Article

\title{
Impact of Externalities on the Design and Management of Multimodal Logistic Networks
}

\author{
Daniela Ambrosino and Anna Sciomachen * (D) \\ Department of Economics and Business Studies, University of Genoa, 16126 Genova, Italy; \\ daniela.ambrosino@economia.unige.it \\ * Correspondence: sciomach@economia.unige.it
}

Citation: Ambrosino, D.;

Sciomachen, A. Impact of

Externalities on the Design and Management of Multimodal Logistic Networks. Sustainability 2021, 13, 5080. https://doi.org/10.3390/ su13095080

Academic Editor: Daniele Manerba and An Caris

Received: 31 March 2021

Accepted: 27 April 2021

Published: 30 April 2021

Publisher's Note: MDPI stays neutral with regard to jurisdictional claims in published maps and institutional affiliations.

Copyright: (c) 2021 by the authors. Licensee MDPI, Basel, Switzerland. This article is an open access article distributed under the terms and conditions of the Creative Commons Attribution (CC BY) license (https:// creativecommons.org/licenses/by/ $4.0 /)$.

\begin{abstract}
It is now widely accepted that the locations of intermediate facilities, such as logistics platforms or inland ports, are key elements of multimodal freight distribution networks and heavily influence their effectiveness. This crucial role of localization decisions is even more significant if we consider their impact on the external costs of the entire logistic corridor, with reference to the cost components associated with environmental sustainability. This paper faces a facility location problem concerning a port system network serving inbound container flows arriving by sea and travelling via road and/or rail towards the hinterland. The aim is to evaluate the impact of externalities on the overall management of the distribution network, including location decisions, flow routing and transport mode choice. We present a Mixed Integer Linear Programming (MILP) model having the goal of minimizing both the location and shipping costs, while accounting for external cost components. In particular, as a novel environmental issue, we propose three different objective functions including congestion, air pollution, and, incidentally, noise and infrastructure deterioration. We allow the containerized flows to be split among several capacitated facilities and road and rail transport modalities. The reported computational experimentation refers to different intermodal freight logistic networks through real data derived from the logistic network departing from the maritime terminals associated with the port of the Ligurian region towards their main destinations in the north-west side of Italy. Finally, we evaluate the impact on both flows and total costs due to a closure or a capacity reduction on some links of the network. The evidence of the impact of sustainability external costs on the design and management of the multimodal logistic network under analysis is emphasized.
\end{abstract}

Keywords: external costs; multimodal transport; facility location problem; freight logistics network

\section{Introduction}

It is well known that logistics and transportation activities are, all over the world, contributing significantly to various environmental damages, such as global warming, air pollution, congestion, noise and other forms of emissions and resource depletion [1-3]. Although these environmental emissions have been reduced in the last decade, those from the transport and logistics sectors are not reducing enough to limit their environmental and climate impacts; these sectors remain a significant source of air pollution, being responsible to more than $23 \%$ of the global emissions and the main source of environmental noise in Europe [4]. In response, transportation and shipping companies are faced with the need to reduce the high environmental costs that result from vehicles, and adopting environmentally sound logistics practices is, globally, increasingly pursued among practitioners [3,5].

From an environmental sustainability point of view, it deserves attention that about $75 \%$ of goods arriving in or leaving Europe are transported by ship, making ports and hinterland connections very important for Europe's growth [4]. Moreover, in the future, we can expect that ports will be even more important and that cargo throughput will 
increase. For this reason, today the problem of sustainability of port logistics is highlighted by many authors, pointing out that cargo volumes arriving by sea necessarily is creating pressures not only on maritime shipping, but also on the port-hinterland connections, which stimulates shippers to develop competitive container supply chains to move cargoes more efficiently [6]. These pressures call for an expansion of seaports toward inland ports [1,7-9]. Note that the phenomenon of naval gigantism, mainly the segment of containerships, has caused a series of consequences not only in terms of infrastructural adjustments of ports but also for the peaks of port congestion and the inland connections, thus negatively impacting on the environmentally sustainability of their surroundings [10]. One main problem that seaports face today is the lack of space at maritime terminals and the growing congestion on their access routes with inland connections, especially considering the road modality [11-14]. Thus, connections with inland transportation often become the weak point for a port, with the risk of nullifying the efforts of the terminal operator in the optimization of quayside and yard operations. Nonetheless, there is still an increasing international container volume worldwide, due to the intensification of global trade.

As already said, many works in the recent literature therefore identify the challenges to designing and implementing eco-innovation practices for port logistic systems, including hinterland connectivity, that require the integration of economic goals and environmental considerations $[6,7,13,15-18]$.

The need to efficiently manage the inland shipment of containers implies decisions concerning the localization of inland ports. Services offered by inland ports have the advantage of reducing the demand on limited seaport capacity, offering shippers the possibility of easy connections to distribution centers that are located farther away from the maritime terminals and closer to the hinterland [8]. The role of inland ports depends on their position within hinterlands and corridors; therefore, in the last decade some location problems have emerged concerning location choices for inland ports. Some authors focus on the 'dry port' concept, which excludes the water-based component of some inland ports (see, e.g., [9,19] for a detailed description of the main functionalities of dry ports). As such, these ports, located further from the maritime access points, serve as a direct link between seaport corridors and the larger hinterland. The study proposed in [11] evaluates potential locations of inland ports that might serve a market through different alternatives, in terms of transport modes, costs and distances, having the additional goal of including the external costs in the decision process.

Internalizing the external costs of transport has been an important issue for transport research and policy development for many years in Europe and worldwide; in particular, very recently attention has been paid to analyze flow patterns in presence of external costs (see e.g., [1,20,21]). A wide number of research projects, supported by the European Commission, suggest that implementing market-based instruments inspired by the economic theoretical concept of marginal social cost pricing could yield considerable benefits [22-24]. In fact, internalization of external costs may lead to a more efficient use of infrastructure, reduce the negative side effects of transport activities and improve fairness between transport users. The Handbooks on external costs estimation [25] present the state of the art and best practice on the methodology for different cost categories. They cover all environmental, accident and congestion costs and consider all transport modes. Environmental-based cost functions accounting for air and noise pollution of vehicles are incorporated in an uncertain environment in [16].

From a management science and operation research point of view, the problem of locating inland ports fits in the class of hub location problems, which in the present case is modelled on multimodal logistics networks [8,26-29]. Multi-modal transportation takes advantage of multiple transport modes and can be an effective way to ease the negative environmental effects of freight transportation [1,11,21].

A hub location problem on logistic networks concerns locating facilities and allocating demand nodes to facilities to route the flow of goods to origin-destination $(o-d)$ minimum cost paths. Most of the recent extensions of facility location problems are modeled on 
multimodal transportation networks and deal with the definition of hubs as intermodal terminals for collecting, dispatching and redistributing flows. Hub location problems in rail-road intermodal networks are faced in $[15,30]$, while a hub location problem for freight mobility in urban multimodal networks is presented in [27]. A more general hub location problem in a multimodal network is addressed in [31,32] with the aim of increasing the modal split in favor of the rail mode, and in [33], where multi-criteria aspects concerning transportation costs and service level are considered. In [13] the authors give an idea of the most typical situations encountered in intermodal spatial transportation problems.

Localization choices strongly depend on the service that has to be performed at the facilities to be selected, as well as on the travelling modes accessible at the facilities and the volume of in/outbound flows passing through them.

A Mixed Integer Linear Programming (MILP) model for choosing the best site for dry ports in a freight logistic multimodal network and validating it through an extensive computational experimentation is proposed in [28]; the study aims at validating the robustness of the model, solved via commercial solver, with respect to the volume of flows and capacity of both the infrastructures and the facilities.

In the present paper we propose a variant of the MILP model proposed in [28] finalized to consider those external cost components in shipping distribution that impact most on environmental sustainability, and to evaluate how such negative impacts affect location decisions and the transport modal split. Therefore, we add the external costs to location and shipping costs to minimize the decision-making process of shippers who have to choose the referring interchange nodes for the cargo loading/unloading operations and the successive transport mode. More precisely, the main aim is to use the MILP model for evaluating the best site for the location of logistic platforms in freight logistics multimodal networks, including rail and road transport modalities, considering existing infrastructures of the logistic network under study.

A similar analysis has been conducted in [11], where pollution and noise external costs were included, while congestion was counted only in the outgoing connections from the ports. The idea was to use the outcomes for improving transport policies and fostering a more efficient and less impacting hinterland transport solution. In this paper, as a novel environmental issue, we have extended to the categories proposed in [24] the external cost due to accidents, congestion and deterioration in all links of the multimodal network.

A multi origins-multi destinations min cost flow problem has been studied in [12], where accidental and polluting costs are considered as external negative costs impacting on collectivity and shipping flows. The authors proposed a novel stepwise function to have externality costs depending on the amount of flow through the capacitated arcs, only considering the road transport modality.

Split deliveries are allowed in the model; in particular, the inbound flows can be split between rail and road transport modes as well as different facilities; demands from many origins to many destinations are combined and routed together for reaching economic benefits. The demand is expressed in terms of units of containerized flow. The MILP model belongs to the field of well-known transportation problems (see for example [34]). As it will be detailed in the next section, we focus on the inbound flow of containers coming from megaships on terminals within the port network of the Liguria county to manage larger quantities of containers in the most environmentally admissible way. We also suggest using the model to analyze the resilience of the multimodal transportation network under investigation and the related social costs. In particular, as a further new perspective, we evaluate the impact on both flows and total costs due to a closure or a capacity reduction of some links of the network from a sustainability point of view.

The remaining of the paper is as follows. The network design problem we are involved with and the environmental sustainability cost included in the decision process are described in detail in Section 2 along with the related multimodal network model. Section 3 presents the proposed MILP formulation of the problem. Section 4 reports the computational experimentation performed with real data derived from the freight logistic 
networks involving the maritime terminals of the port of the Ligurian region and the main logistic platforms in the north-west side of Italy. An analysis of the resilience of the proposed network in terms of increased congestion and environmental impact costs caused by disruptions in some legs of the logistics network is also given. Finally, some conclusions and an outline for future works are reported.

\section{Problem Definition and the Related Multimodal Logistic Network Model}

We consider a multimodal logistic network model in which goods, from their origin node $o$, can reach their destination node $d$ by a single transport modality (that is, by a direct link from $o$ to $d$ ) or by an intermodal transport passing through intermodal terminals. Let us consider only rail and road modalities. As far as intermodal transport is considered, the following alternatives can be mentioned:

- Road-rail-road

- Rail-rail-road

- Rail-road

The road-rail-road combination is typical of door to door services; rail-road combination is usually used for transferring goods from one terminal to door; and finally, rail-rail-road can be found in large networks having ports linked to dry ports and organized according to a hub and spoke criterion.

The efficiency and the total cost of the different above-mentioned $o-d$ transport solutions are strongly dependent on both the location of the facilities and the rail transport system. Shipping freight through terminals requires respecting fixed train schedules and paying more handling costs; conversely, the savings in the externality costs can be significant. Except in special cases, where urgency in the shipment may require road transport, it is generally more convenient to use road transport only in the first and last mile of the shipment.

Before introducing the problem under investigation in detail, we will briefly discuss the external costs.

\subsection{External Costs}

The external costs due to transport activities have been classified as follows:

1. Congestion;

2. Accidents;

3. Noise;

4. Air pollution;

5. Infrastructure wear and tear for road and rail.

A deep discussion on these is reported in some documents of the European community [23] and the most recent update is presented in [24].

$83 \%$ of these costs are related to road transport. In European countries, external costs due to freight transport range from 3.4\% to $7 \%$ of the Gross Domestic Product (GDP), with an average value that is $6.6 \%$ for UE ( $4.8 \%$ of GDP when congestion costs are not included).

The graphs in Figure 1 report the share of the different cost categories on the total external costs (Figure 1a) and the share of the different transport modes on the total external costs (Figure 1b).

Note that economic environment and land use structure have an influence on the transportation systems and thus on the external costs. In addition, the type of roads, type of vehicles, and time of day (and relative traffic versus road capacity) also have an impact on the external costs. For these reasons, the external costs included in the proposed analysis are average values among different Euro classes of trucks, or Heavy Good Vehicles (HGV); they are shown in Table 1 expressed in Euro-cent/tkm [24]. 

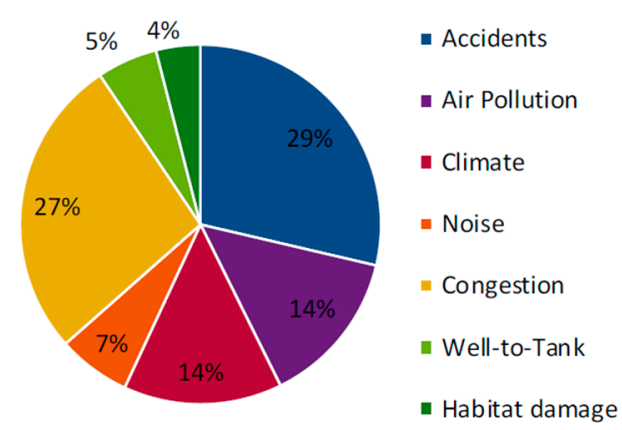

Including data for aviation and maritime: rough estimations for EU28.

(a)

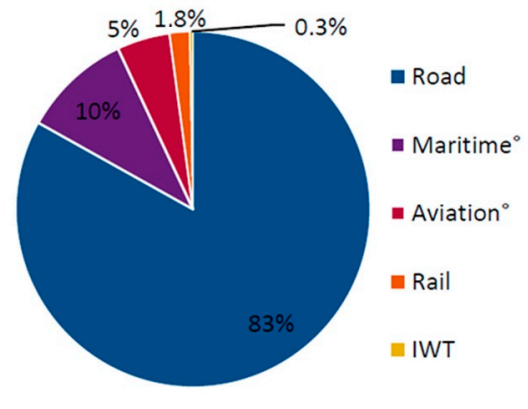

Data for aviation and maritime: rough estimations for EU28.

(b)

Figure 1. Share of: (a) different cost categories and (b) different transport modes on total external costs (adapted from [24]).

Table 1. Environmental cost: average among different Euro classes of trucks, in Euro-cent/tkm.

\begin{tabular}{cccccc}
\hline & Congestion & Noise & Accidents & $\begin{array}{c}\text { Air } \\
\text { Pollution }\end{array}$ & Deterioration \\
\hline Road & 0.8 & 0.5 & 1.3 & 0.8 & 0.2 \\
\hline Rail & 0 & 0.6 & 0.1 & 0.2 & 0.2 \\
\hline
\end{tabular}

\subsection{The Multimodal Logistic Network Model}

In the present problem, we are involved in a logistic network where origin nodes are seaports, destination nodes are either final destinations or connections to the main transportation corridors, while facilities are either inland ports or logistic platforms. Thus, intermodal transport allows for combining rail-rail and rail-road modes.

Note that the multimodal logistics network considered here is derived from that originally proposed in [28]. More precisely, in this work we focus only on the inbound flows from any origin node, i.e., maritime terminals, to destination ones.

The objective of the problem is to design an efficient multimodal logistic network to serve a set of origin-destination demands in such a way to minimize total logistic costs and meet capacity constraints related to both facilities and arcs. Thus, having a set of potential facility nodes with their capacities and costs, the problem is to determine which facilities to select and how to serve the $o-d$ demands in such a way as to minimize transportation and external costs, fixed costs to activate the inland terminals, generally called facilities, and handling costs at the inland terminals. Each facility has a capacity related to handling activities and the maximum number of trucks and trains that can be managed. The transport demand is expressed in terms of container units.

The present network design problem is modelled with a weighted digraph $G=(V, E)$, where $V$ is the set of nodes and $E$ is the set of arcs, connecting pairs of nodes. Weights are associated with both nodes and arcs of the network. Arc weights represent the travel cost (in $€ / \mathrm{km}$ ) to pass through the considered arc using the available transport modes. These usually depend on the distance. Moreover, each arc has a given capacity for each transport modality, i.e., rail and road. Recall that all facility nodes are multimodal nodes. Further, note that the number of facilities to choose is not fixed in advance, as in [26,30], but is a decision variable.

More precisely, referring to the specificity of the present problem, the main decisions concern the number of facilities to locate and their location, together with the transportation modalities to be used to ship the required volume of containers from origins to destinations through the selected logistic platforms.

Finally, no shipment transit time, or service time, between $o-d$ nodes is included in the analysis. In fact, here we are not interested in optimising the time spent by each unit of containerized flow within the $o-d$ chosen path, as, for instance, in the aforementioned 
works $[26,30]$ where service time is included. The focus here is to assess the impact of externality costs on both location decisions and flows on the network.

Let us describe graph $G$ in more detail. Set $V$ of nodes of the network is the union of three sub-sets, representing, respectively, the origin nodes $\left(V_{O}\right)$, the destination nodes $\left(V_{D}\right)$, and potential facility nodes $\left(V_{F}\right)$. Thus, $V$ is given by $V=V_{O} \cup V_{D} \cup V_{F}$, such that $V_{O} \cap V_{D} \cap V_{F}=\varnothing$. Set $E$ of arcs of the network is the union of two sub-sets, representing, respectively, the road $(r)$ and rail $(w)$ modalities. Thus $E=E_{r} \cup E_{w}$. Finally, $D$ is the set of transport demand $(o, d)$ from origin node $o$ to destination node $d, \forall o \in V_{O}, d \in V_{D}$. An example of possible connections for the inbound flows leaving from seaports towards inland destinations within the multimodal logistic network $G$ is reported in Figure 2, where the origin nodes belonging to $V_{O}$, here modelling seaports, are represented by hexagons, transition nodes belonging to $V_{F}$ are depicted by triangles and destination nodes belonging to $V_{D}$ are represented by squares. The arcs modelling the road connections are represented by solid lines, while dotted lines are the arcs of the rail transportation network.

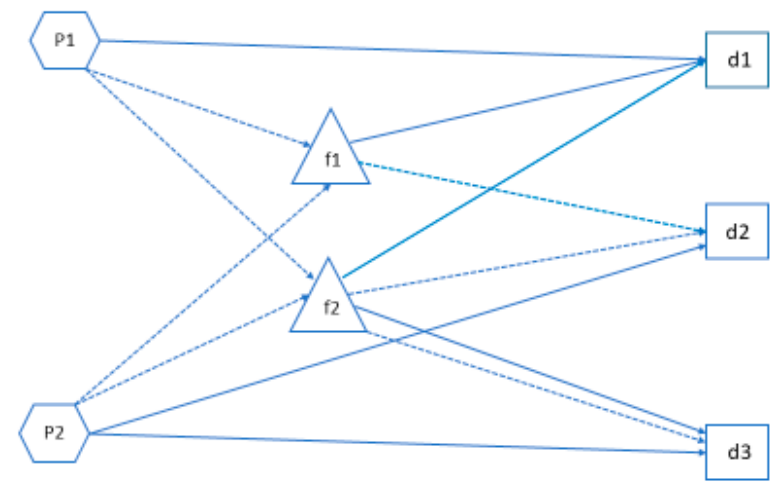

Figure 2. An example of inbound flows in a multimodal logistic network.

\section{The proposed MILP Model with External Costs}

In this Section a MILP model for the problem under investigation is introduced.

\subsection{The Required Notation}

Before presenting the model, it can be useful to briefly summarize the required notation, which strongly relies on the multimodal logistic network described in the previous Section.

The useful notation is the following.

\subsubsection{Sets and Indexes}

$M$

$\mathrm{V}=V_{O} \cup V_{D} \cup V_{F}$

$V_{O} \subset V$

$V_{D} \subset V$

$V_{F} \subset V$

$E=E_{r} \cup E_{w}$

$E_{r} \subset E$

$E_{w} \subset E$

$D$ set of available transport modalities (here road $(r)$ and rail $(w)$ );

set of nodes of graph G;

set of origin nodes;

set of destination nodes;

set of potential facility nodes;

set of arcs of graph $G$;

set of arcs of road modality;

set of arcs of rail modality;

set of transport demand $(o, d)$ from origin $o$ to destination node $d$, $\forall o \in V_{O}, d \in V_{D}$. 


\subsubsection{Constants}

$c_{i j}^{m} \quad$ cost for shipping one container along arc $(i, j)$ with modality $m, \forall m \in M,(i, j) \in E_{m}$;

$e_{i j}^{m}$ overall external costs for shipping one container along arc $(i, j)$ with modality $m$, $\forall m \in M,(i, j) \in E_{m}$;

$o_{f} \quad$ fixed cost for a facility at node $f, \forall f \in V_{F}$;

$h_{f}^{m} \quad$ unit handling cost for containers reaching/leaving facility $f$ with modality $m, \forall m \in M$, $\forall f \in V_{F}$;

$k_{f} \quad$ maximum handling capacity of facility $f, \forall f \in V_{F}$;

$t_{f}^{m}$ in/out daily handling capacity of facility $f$, for modality $m, \forall f \in V_{F}, \forall m \in M$;

$d_{o d}$ transport demand from origin node $o$ to destination node $d, \forall(o, d) \in D$;

$q_{i j}^{m} \quad$ flow capacity of arc $(i, j)$ with modality $m, \forall m \in M, \forall(i, j) \in E_{m}$.

\subsubsection{Variables:}

$x_{i f m}^{o d} \geq 0, \forall i \in V_{O}, f \in V_{F}, m \in M, \forall(o, d) \in D$, such that $o=i$, flow variables indicating the quantity of demand $(o, d)$ from node $i$ to node $f$, shipped by modality $m$;

$y_{f j m}^{o d} \geq 0, \forall f \in V_{F}, j \in V_{D}, m \in M, \forall(o, d) \in D$, such that $d=j$, flow variables indicating the quantity of demand $(o, d)$ from node $f$ to node $j$, shipped by modality $m$;

$z_{i j m}^{o d} \geq 0, \forall i \in V_{O}, j \in V_{D}, m \in M, \forall(o, d) \in D$, such that $o=i, d=j$, flow variables indicating the quantity of demand $(o, d)$ directly shipped by modality $m$ from node $i$ to node $j$;

$u_{f} \in\{0,1\}, \forall f \in V_{F}$ : facility activation variables indicating which facility nodes are chosen; in particular, $u_{f}=1$ if node $f$ is chosen, $u_{f}=0$ otherwise.

\subsection{The MILP Model}

The MILP model for evaluating the external costs of shipping inbound containers to inland destinations via a combined road and rail logistics network is shown below.

$$
\min _{i \in V_{O} f \in V_{F}} \sum_{\substack{(o d) \in D: \\ o=i}} \sum_{m \in M}\left(c_{i f}^{m}+e_{i f}^{m}\right) x_{i f m}^{o d}+\sum_{f \in V_{F}} \sum_{j \in V_{D}} \sum_{\substack{(o d) \in D: \\ j=d}} \sum_{m \in M}\left(c_{f j}^{m}+e_{f j}^{m}\right) y_{f j m}^{o d}+\sum_{i \in V_{O}} \sum_{j \in V_{D}} \sum_{\substack{(o d) \in D: \\ 0=i, d=j}} \sum_{m \in M}\left(c_{i j}^{m}+e_{i j}^{m} z_{i j m}^{o d}+\right.
$$

subject to

$$
\begin{gathered}
\sum_{m \in M} \sum_{f \in V_{F}} y_{f j m}^{o d}+\sum_{m \in M} \sum_{i \in V_{o}} z_{i j m}^{o d} \geq d_{o d} \forall j \in V_{D}, \forall(o, d) \in D: d=j \\
\sum_{m \in M} \sum_{f \in V_{F}} x_{i f m}^{o d}+\sum_{m \in M} \sum_{j \in V_{D}} z_{i j m}^{o d} \geq d_{o d} \forall i \in V_{O},(o, d) \in D: o=i \\
\sum_{m \in M} \sum_{i \in V_{O}} \sum_{\substack{(o d) \in D \\
o=i}}^{o d} x_{i f m}^{o d} \leq k_{f} u_{f} \forall f \in V_{F} \\
\sum_{i \in V_{O}} \sum_{(o d) \in D:} x_{i f m}^{o d}+\sum_{j \in V_{D}} \sum_{\substack{(o d) \in D \\
d=j}} y_{f j m}^{o d} \leq t_{f}^{m} u_{f} \forall m \in M, \quad \forall f \in V_{F} \\
\sum_{(o d) \in D:} x_{i f m}^{o d} \leq q_{i f}^{m} \forall i \in V_{O}, \quad \forall f \in V_{F}, \forall m \in M
\end{gathered}
$$




$$
\begin{aligned}
& \sum_{\substack{(o d) \in D: \\
d=j}} y_{f j m}^{o d} \leq q_{f j}^{m} \quad \forall f \in V_{F}, \forall j \in V_{D}, \forall m \in M \\
& z_{i j m}^{i j} \leq q_{i j}^{m} \forall i \in V_{O}, \quad \forall j \in V_{D}, \forall m \in M \\
& \sum_{m \in M} \sum_{\substack{i \in V_{O} \\
(o d) \in D: \\
o=i}} x_{i f m}^{o d}=\sum_{m \in M} \sum_{j \in V_{D}} \sum_{\substack{(o d) \in D: \\
d=j}} y_{f j m}^{o d} \quad \forall f \in V_{F} \\
& x_{i f m}^{o d} \geq 0, \forall i \in V_{O}, f \in V_{F}, \in M \forall(o d) \in: o i \\
& y_{f j m}^{o d} \geq 0, \forall f \in V_{F}, j \in V_{D}, m \in M, \forall(o, d) \in D: d=j \\
& z_{i j m}^{o d} \geq 0, \forall i \in V_{O}, j \in V_{D}, m \in M, \forall(o, d) \in D: o=i, d=j \\
& u_{f} \in\{0,1\}, \forall f \in V_{F}
\end{aligned}
$$

The objective function (1) minimizes the overall costs, including traveling and external costs, activation, and handling costs at the facility nodes.

Constraints (2) and (3) are related to the (o,d) demand to satisfy. Constraints (4) define the maximum handling capacity of the facilities. Constraints (5) are related to the capacity of the facility nodes to receive and ship freights according to the incoming/outgoing transport modalities. Note that all capacity constraints (2)-(5) are active only if the corresponding facility node $f$ is selected (i.e., $u_{f}=1$ ); otherwise, no flow can enter or leave node $f$. Constraints (6)-(8) express the capacity of the arcs with respect to their transport mode. Finally, (10) defines the decision variables.

\section{Analysis of the Results of the Proposed MILP Model. Evaluation of the Environmental Impact in a Case Study}

In this section we analyze the logistic network of the north western side of Italy used to manage the import flows from the three main ports of the Ligurian region towards northern Italy destinations.

Freight destinations can be distinguished into end-customers that must be served by trucks, and nodes connecting to European corridors that can also be served by rail and are served by rail if possible.

As already said, our aim is to evaluate the impact of the aforementioned external costs on both the flows along the network and the modal split into the decision process. Secondly, we use a model (1)-(10) to evaluate some changes that may occur on the network due to special events that may result in closure or a drastic reduction of the capacity in a part of the network.

The transportation network under investigation is depicted in Figure 3, along with the related graph model.
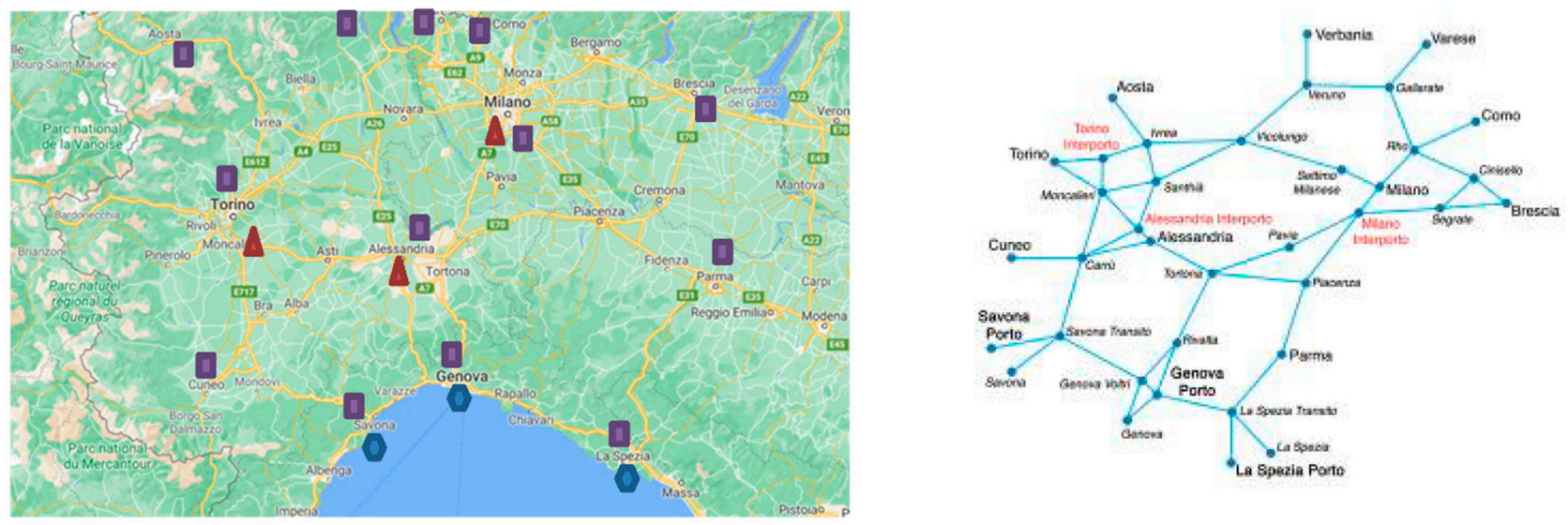

Figure 3. The transportation network of the area under study and the related graph model. 
The set of nodes of $G$ consists of 3 origin modes (i.e., the ports), 3 intermodal facilities and 12 destination nodes. Thus, the inbound flows to manage are given by the pairs of $o-d$ demands.

We considered three potential intermodal facilities, those that were most appropriate based on the total volume that needs to be handled in the network under consideration.

\subsection{Impact of External Costs on the Flow Routing and Transport Mode Choice}

The MILP model presented in Section 3.2 has been used to assess the impact of the sustainability external costs on the site of the intermodal facilities, the flow routing and the resulting modal split between road and rail ones. Note that this analysis has been conducted assuming three different scenarios in terms of capacity limitations. These scenarios present the following characteristics:

- Net0: no limitations on flows on the connections and inside the facilities

- Net1: the intermodal platforms have limited capacity in handling trucks and trains (60 trucks and 3 trains per day, each with a capacity of 60 TEUs);

- Net2: intermodal platforms have a limited capacity in the handling of trucks and trains which is double that of Net1 (120 trucks and 6 trains per day).

The Net1 and Net2 scenarios refer to two capacitated networks and more realistically represent the network under consideration

In the considered network, rail transport represents a good alternative to the shipment of goods, thanks also to the fact that the rail network is present in all the identified logistic platforms. Therefore, the identified network described above with three operational intermodal nodes is optimally designed.

It is worth noting that the presence of external costs does not impact on the network infrastructure but on the chosen transport modalities.

To assess the impact of different external cot components from a sustainability point of view, model (1)-(10) has been solved by modifying the objective function (1) to minimize, respectively:

(i) Facilities and transportation costs;

(ii) Facilities, transportation and the external costs without deterioration costs;

(iii) Facilities, transportation and all the external costs mentioned in Table 1.

Table 2 reports the results obtained using the proposed MILP model on the network shown in Figure 3, assuming initially that the network has no limitation on the amounts of flow passing on the arcs and through the intermodal facilities, so as to identify the best paths without any limitation due to the capabilities of arcs and nodes (Scenario Net0). The data for this scenario are shown in row Net0 of Table 2. The last two rows refer to the capacitated scenarios.

Table 2. \% split modality in the network.

\begin{tabular}{|c|c|c|c|c|c|c|c|c|}
\hline \multirow{2}{*}{ Scenarios } & \multicolumn{4}{|c|}{ No_External_Costs-Obj Function (i) } & \multicolumn{4}{|c|}{$\begin{array}{l}\text { Congestion\&Noise\&Pollution } \\
\text { \&Accident\&Deterioration-Obj Function (iii) }\end{array}$} \\
\hline & o-Hub & $\begin{array}{l}\text { Hub-d } \\
\text { (Road) }\end{array}$ & $\begin{array}{c}\text { Hub-d } \\
\text { (Rail) }\end{array}$ & o-d & o-Hub & $\begin{array}{l}\text { Hub-d } \\
\text { (Road) }\end{array}$ & $\begin{array}{c}\text { Hub-d } \\
\text { (Rail) }\end{array}$ & o-d \\
\hline Net0 & 71.31 & 36.22 & 35.09 & 28.69 & 74.38 & 29.12 & 45.25 & 25.62 \\
\hline Net1 & 22.58 & 4.52 & 18.06 & 77.42 & 24.84 & 9.03 & 15.80 & 75.16 \\
\hline Net2 & 45.16 & 9.03 & 36.12 & 54.84 & 49.67 & 18.06 & 31.61 & 50.33 \\
\hline
\end{tabular}

Table 2 shows for each scenario, Net0, Net1, and Net2, the differences in the modal split when the model is solved with objective function (i), i.e., without external costs, and with objective function (iii), i.e., with all external costs shown in Table 1. In particular, the total demand leaving the origin nodes (set at 100\% of the goods in the network) can be either shipped directly to the destination (by road) or can be shipped through the hub. 
Goods reach the hub by rail and can continue their shipment to their final destinations either by road or by rail. The total amount of goods reaching the destination $(100 \%)$ can be split into the \% of direct shipment by road (column o-d), the \% of goods leaving the hub by road (column hub-d (road)) and by rail (column hub-d (rail)).

As already said, in all cases, the three potential hubs are operational, as their presence allows for reduced transportation costs.

Note that in all cases the incidence of hub costs on total logistic costs is low: it ranges from $2.17 \%$ in the case of Net1, where the hub capacity is more limited, to $13.73 \% \%$ in Net0 which represents the unlimited capacitated network.

In this ideal situation (Net0), including only logistics platform costs and transportation costs in the decision-making process, as the rail cost per unit of UTI is lower than the road cost, a large proportion of goods are generally shipped by rail. More precisely, $71.31 \%$ of the goods leave the ports by rail (to reach the logistics platforms) and half of them (35.09\%) continue their journey to the destination by rail.

When external costs are included, this percentage grows to $74.38 \%$, and $45.25 \%$ of total flows arrive at their destination by rail. This change in modal split represents a first step towards a more sustainable transport system. In fact, the costs of the transport system (corresponding to transport costs and external ones) show a reduction in terms of congestion and air pollution that is about $1.6 \%$, that is, equal to $3 \mathrm{ML} €$. This reduction increases to $3 \%$, that is, $5.5 \mathrm{ML} €$, if we also include the external costs due to accidents.

Looking at Table 2, it can be seen that the modal split is quite different in Net1, where strong capacity constraints are imposed at the intermodal nodes. Here, in fact, only $22.58 \%$ of goods leave the ports by rail and $18.06 \%$ arrive at their destination by rail. Thanks to the internalization of external costs (i.e., here expressed by objective function (iii)), these percentages grow to $24.84 \%$ for flows leaving ports, while the percentage of goods leaving the intermodal nodes by rail to reach their final destination is $15.80 \%$.

Let us consider the costs associated with transportation activities (i.e., transportation and external costs) and set this amount at $100 \%$. The main aim is to assess the environmental impact of external costs when they are included in the decision process. Table 3 shows the percentage composition of transportation and external costs paid by the community. It can be seen that by including external costs, total system costs decrease and there is a change in the composition of total costs. In particular, the share of external costs in the total shows a small decrease, while among the different types of external costs included in the analyses deterioration costs increase, thus showing an opposite trend.

Table 3. Percentage cost composition.

\begin{tabular}{ccccccccc}
\hline \multirow{2}{*}{ Scenarios } & \multicolumn{3}{c}{ No_External_Costs-Obj Function (i) } & \multicolumn{3}{c}{$\begin{array}{c}\text { Congestion\&Noise\&Pollution } \\
\text { \&Accident\&Deterioration-Obj Function (iii) }\end{array}$} \\
\cline { 2 - 9 } & $\begin{array}{c}\text { Transport } \\
\text { Costs }\end{array}$ & $\begin{array}{c}\text { Congestion } \\
\text { Costs }\end{array}$ & $\begin{array}{c}\text { Deterior. } \\
\text { Costs }\end{array}$ & $\begin{array}{c}\text { Other ext. } \\
\text { Costs }\end{array}$ & $\begin{array}{c}\text { Transport } \\
\text { Costs }\end{array}$ & $\begin{array}{c}\text { Congestion } \\
\text { Costs }\end{array}$ & $\begin{array}{c}\text { Deterior. } \\
\text { Costs }\end{array}$ & $\begin{array}{c}\text { Other ext. } \\
\text { Costs }\end{array}$ \\
\hline Net0 & 43.88 & 4.15 & 7.84 & 44.12 & 44.79 & 3.39 & 8.11 & 43.71 \\
Net1 & 33.02 & 13.25 & 4.65 & 49.08 & 33.48 & 12.87 & 4.78 & 48.87 \\
Net2 & 37.22 & 9.73 & 5.88 & 47.16 & 38.40 & 8.74 & 6.23 & 46.62 \\
\hline
\end{tabular}

It is possible to analyze in more detail the variation in external costs due to a different level of internalization of external costs by using objective functions (ii) and (iii) where deterioration costs are also included. Figure 4 reports the cost variation of all external costs mentioned in Table 1 and the modal split in the cases of objective function (ii) (blue) and objective function (iii) (orange) for the Net0 scenario. From Figure 4 it is possible to note that the greatest variations concern the transport modality used and the congestion costs. A more detailed analysis is reported in Table 4 


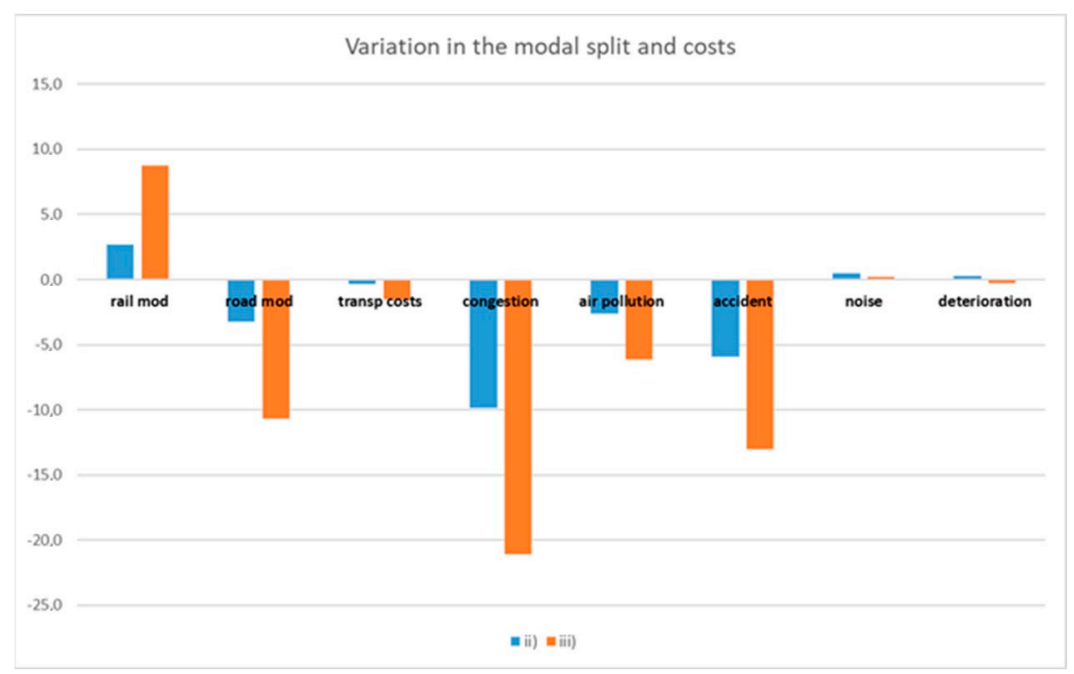

Figure 4. Variation in the split modality and external costs due to a different level of internalization of external costs.

Table 4. Split modality and cost composition.

\begin{tabular}{ccccccccc}
\hline $\begin{array}{c}\text { Obj } \\
\text { Function }\end{array}$ & Rail Mod & Road Mod & $\begin{array}{c}\text { Transport } \\
\text { Costs }\end{array}$ & $\begin{array}{c}\text { Congestion } \\
\text { Costs }\end{array}$ & $\begin{array}{c}\text { Air } \\
\text { Pollution } \\
\text { Costs }\end{array}$ & $\begin{array}{c}\text { Accident } \\
\text { Costs }\end{array}$ & $\begin{array}{c}\text { Noise } \\
\text { Costs }\end{array}$ & $\begin{array}{c}\text { Deterioration } \\
\text { Costs }\end{array}$ \\
\hline (ii) & 2.7 & -3.2 & -0.4 & -9.8 & -2.6 & -5.9 & 0.5 & 0.3 \\
\hline (iii) & 8.7 & -10.7 & -1.5 & -21.1 & -6.2 & -13.0 & 0.2 & -0.2 \\
\hline
\end{tabular}

Note that internalizing external costs in decision making shifts some of the road transport to the rail mode. Road transport drops from $28.69 \%$ to $25.62 \%$ of the total transportation cost. Congestion cost savings reach $21.07 \%$ in a full internalization process, while air pollution and accident cost savings are $6.16 \%$ and $13.02 \%$, respectively. The total cost reduction related to transportation activities due to the inclusion of external costs is $1.87 \%$ (corresponding to $6.66 \mathrm{ML} €$ ), while in the case of a capacitated network, for example Net1, this reduction is about $3.85 \%$ (more than $7.1 \mathrm{ML} €$ ).

It is worth observing that the last mile is usually served by trucks. In fact, door to door services require the last portion of trips to be made by truck. Some works are in progress to improve the truck services, saving kilometres of travel by combining trips and permitting movement towards more sustainable transport systems.

In this paper we are not investigating the cooperation in truck services from facilities to final destinations and vice versa; interested readers can refer to $[35,36]$.

\subsection{Evaluation of Network Interruptions on the Society Costs}

A very interesting aspect of the present study is the possibility of using models (1)-(10) to help authorities evaluate the impact on both flows and total costs of a closure or a large reduction in the capacity of a part of a network. Moreover, when an arc suffers from deterioration and it is desired to preserve it, it is possible to move the flow along different arcs of the network. At the same time, it is possible to evaluate the impact of decisions made on the choice of routes, the use of logistics platforms and the transport mode for shipping companies using the logistics network in terms of external costs paid.

To the authors' knowledge, there is no work related to the evaluation of the environmental impact due to disruption events on networks from this perspective.

To prevent a problem on an arc that presents criticalities, it is possible to modify the deterioration cost of the part of the network that contains this arc in such a way to suggest the use of different routes and/or different modalities. The variation of the total costs 
that involve such modification of the route previously planned represents the social cost. Among different solutions it is possible to evaluate the most sustainable one.

Remembering recent events in the Ligurian motorway and their impact on traffic congestion (i.e., congestion due to the collapse of the Morandi Bridge on 14 August 2018 and congestion due to tunnel works on motorways to/from Piedmont that began in summer 2020), the authorities can increase the congestion costs related to that part of the network and therefore suggest the use of different routes and/or different modes and assess the impact of these changes on society accordingly.

To give an example, suppose we have an interruption of the rail connection to the logistic platforms located in Turin (see Figure 3). The proposed model allowed us to investigate the effect of this transportation service interruption on freight flows and costs. Table 5 shows the changes in the flow partition (\% split modality) and in the composition of costs (\% costs composition) passing from the original network (row Net1) to the damaged one (row Net-noTO).

Table 5. Split modality and cost composition.

\begin{tabular}{|c|c|c|c|c|c|c|c|c|c|}
\hline \multirow[b]{2}{*}{ Scenarios } & \multicolumn{4}{|c|}{$\%$ Split Modality } & \multicolumn{5}{|c|}{$\%$ Costs Composition } \\
\hline & o-Hub & $\begin{array}{l}\text { Hub-d } \\
\text { (Road) }\end{array}$ & $\begin{array}{c}\text { Hub-d } \\
\text { (Rail) }\end{array}$ & o-d & $\begin{array}{l}\text { Facilities } \\
\text { Costs }\end{array}$ & $\begin{array}{c}\text { Transport } \\
\text { Costs }\end{array}$ & $\begin{array}{l}\text { Congestion } \\
\text { Costs }\end{array}$ & $\begin{array}{l}\text { Deterior. } \\
\text { Costs }\end{array}$ & $\begin{array}{l}\text { Other ext. } \\
\text { Costs }\end{array}$ \\
\hline Net & 24.84 & 9.03 & 15.80 & 75.16 & 2.43 & 32.66 & 12.56 & 4.67 & 47.68 \\
\hline Net-noTO & 15.80 & 4.52 & 11.29 & 84.20 & 1.42 & 31.95 & 13.57 & 4.41 & 48.66 \\
\hline
\end{tabular}

We have assumed scenario Net1 and we have solved models (1)-(10) with objective function (iii). The total costs increase by about $9.39 \%$, corresponding to more than $€ 32$ million. Congestion and air pollution costs increase by about $14.51 \%$ and $10.78 \%$, respectively; the accident cost increases by about $13.3 \%$.

\section{Conclusions}

In summary, in this paper we showed how, using an optimization model, it is possible to assess the impact of external costs to design and manage sustainable logistics networks. We focus on shipping distribution multimodal networks of containerized flows from ports to inland destinations. We showed how including external costs, such as congestion, noise, air pollution, accidents, and deterioration, can change the structure of a multimodal network and the management of import flows. In particular, in order to have more sustainable shipping plans, the internalization of external costs in the decision-making process has to shift a portion of road transport to rail mode.

This is particularly true since this observation has been derived from the results obtained by testing different objective functions on the transportation system related to the north west of Italy, where the modal split is remarkably unbalanced in favor of the road modality. For shipping companies, the greenest land transport mode for freight is rail.

We have analyzed some scenarios; the reported results show that the biggest limitation of rail mode is the infrastructure capacity, both the intermodal facilities and their connections, represented by the arcs of the related graph model. More precisely, when a transport network is close to a saturation level it is difficult to move toward greener mobility. From all scenarios, the total cost reduction related to transport activities when external costs are considered varies from about 6.5 ML $€$ to 7 ML $€$, depending on the amount of flow along the network.

Finally, the same conclusion can be derived when emergencies, such as service interruptions, occur along the network. In fact, in the last analysis proposed in this paper we stress that the higher the network's ability to switch between modes, or to use alternative and unsaturated routes, the lower the negative impact of externalities on society, especially with respect to environmental sustainability. 
Author Contributions: The Author Contributions are considered equal in all parts of the article. both authors have read and agreed to the published version of the manuscript.

Funding: This research received no external funding.

Institutional Review Board Statement: Not applicable.

Informed Consent Statement: Not applicable.

Data Availability Statement: The data presented in this study are available on request from the corresponding author.

Conflicts of Interest: The authors declare no conflict of interest.

\section{References}

1. Dong, B.; Christiansen, M.; Fagerholt, K.; Chandra, S. Design of a sustainable maritime multi-modal distribution network-Case study from automotive logistics. Transp. Res. Part E 2020, 143, 102086. [CrossRef]

2. Khan, S.A.R.; Sharif, A.; Golpîra, H.; Kumar, A. A green ideology in Asian emerging economies: From environmental policy and sustainable development. Sustain. Dev. 2019, 27, 1063-1075. [CrossRef]

3. Jazairy, A. Aligning the purchase of green logistics practices between shippers and logistics service providers. Transp. Res. Part D 2020, 82, 102305. [CrossRef]

4. European Environment Agency-EEA. 2019. Available online: https://europa.eu/european-union/about-eu/agencies/eea_it (accessed on 1 October 2019).

5. Evangelista, P.; Santoro, L.; Thomas, A. Environmental sustainability in third-party logistics service providers: A systematic literature review from 2000-2016. Sustainability 2018, 10, 1627. [CrossRef]

6. Haezendonck, E.; Dooms, M.; Verbeke, A. A new governance perspective on port-hinterland relationships: The Port Hinterland Impact (PHI) matrix. Marit. Econ. Logist. 2014, 16, 229-249. [CrossRef]

7. Dai, Q.; Yang, J.; Li, D. Modeling a Three-Mode Hybrid Port-Hinterland Freight Intermodal Distribution Network with Environmental Consideration: The Case of the Yangtze River Economic Belt in China. Sustainability 2018, 10, 3081. [CrossRef]

8. Racunica, I.; Wynter, L. Optimal location of intermodal freight hubs. Transp. Res. B 2005, 39, 453-477. [CrossRef]

9. Roso, V.; Lumsden, K. A review of dry ports. Marit. Econ. Logist. 2010, 12, 196-213. [CrossRef]

10. Haralambides, H.E. Gigantism in container shipping, ports and global logistics: A timelapse into the future. Marit. Econ. Logist. 2019, 21, 1-60. [CrossRef]

11. Ambrosino, D.; Ferrari, C.; Sciomachen, A.; Tei, A. Intermodal nodes and external costs: Re-thinking the current network organization. Res. Transp. Bus. Manag. 2016, 19, 106-117. [CrossRef]

12. Ambrosino, D.; Sciomachen, A.; Surace, C. Evaluation of flow dependent external costs in freight logistics networks. Networks 2019, 74, 111-123. [CrossRef]

13. Arnold, P.; Peeters, D.; Thomas, I. Modeling a rail/road intermodal transportation system. Transp. Res. E 2004, 40, 255-270. [CrossRef]

14. Orjia, I.J.; Kusi-Sarpongb, S.; Guptac, H.; Okwu, M. Evaluating challenges to implementing eco-innovation for freight logistics sustainability in Nigeria. Transp. Res. Part A Policy Pract. 2019, 129, 288-305. [CrossRef]

15. Limbourg, S.; Jourquin, B. Optimal rail -road container terminal locations on the European network. Transp. Res. E 2009, 45, 551-563. [CrossRef]

16. Mohammadi, M.; Torabi, S.A.; Tavakkoli-Moghaddam, R. Sustainable hub location under mixed uncertainty. Transp. Res. Part E 2014, 62, 89-115. [CrossRef]

17. Trappa, A.C.; Harrisb, I.; Rodriguesb, V.S.; Sarkis, J. Maritime container shipping: Does coopetition improve cost and environmental efficiencies? Transp. Res. Part D 2020, 87, 102507. [CrossRef]

18. Twrdy, E.; Zanne, M. Improvement the sustainability of ports logistics by the development of innovative green infrastructure solutions. Transp. Res. Procedia 2020, 45, 539-546. [CrossRef]

19. Roso, V.; Woxenius, J.; Lumsden, K. The dry port concept: Connecting container seaports with the hinterland. J. Transp. Geogr. 2009, 17, 338-345. [CrossRef]

20. Demir, E.; Huang, Y.; Scholts, S.; Van Woensel, T. A selected review on the negative externalities of the freight transportation: Modeling and pricing. Transp. Res. Part E 2015, 77, 95-114. [CrossRef]

21. Iannone, F. The private and social cost efficiency of port hinterland container distribution through a regional logistic system. Transp. Res. A 2012, 46, 1424-1448. [CrossRef]

22. CE Delft, Infras, Fraunhofer ISI. External Costs of Transport in Europe-Update Study for 2008; CE Delft: Delft, The Netherlands, 2011.

23. Ricardo-AEA Report ED57769. Final Report for the European Commission "Transport and Environmental Policy Research"; DG MOVERicardo-AEA/R/ ED57769, Ricardo-AEA: Harwell, UK, January 2014.

24. Ricardo-AEA Annual Report 2018/19. 2019. Available online: https://ricardo.com/investors/financial-reporting/annualreports/2018-19/annual-report-2018-19 (accessed on 1 October 2019). 
25. Maibach, M.; Schreyer, C.; Sutter, D.; van Essen, H.P.; Boon, B.H.; Smokers, R.; Schroten, A.; Doll, C.; Pawlowska, B.; Bak, M. Handbook on Estimation of External Costs in the Transport Sector; Version 1.1. (2008 Handbook); CE Delft: Delft, The Netherlands, 2008.

26. Alumur, S.A.; Kara, B.Y.; Karasan, O.E. Multimodal hub location and hub network design. Omega 2012, 40, 927-939. [CrossRef]

27. Ambrosino, D.; Sciomachen, A. Hub Locations in Urban Multimodal Networks. European Transport, 2012; Volume 51, ISSN 1825-3997.

28. Ambrosino, D.; Sciomachen, A. A Capacitated Hub Location Problem in Freight Logistics Multimodal Networks. Optim. Lett. 2016, 10, 875-901. [CrossRef]

29. Rahimi, M.; Asef-Vaziri, A.; Harrison, R. An Inland port location-allocation model for a regional intermodal goods movement system. Marit. Econ. Logist. 2008, 10, 362-379. [CrossRef]

30. Ishfaq, R.; Sox, C.R. Hub location-allocation in intermodal logistic networks. Eur. J. Oper. Res. 2011, 210, 213-230. [CrossRef]

31. Pittman RJandová, M.; Król, M.; Nekrasenko, L.; Paleta, T. The effectiveness of EC policies to move freight from road to rail. Res. Transp. Bus. Manag. 2020, 37, 100482. [CrossRef]

32. Mostert, M.; Caris, A.; Limbourg, S. Road and intermodal transport performance: The impact of operational costs and air pollution external costs. Res. Transp. Bus. Manag. 2017, 23, 75-85. [CrossRef]

33. López-Ospina, H.; Agudelo-Bernal, A.; Reyes-Muñoz, L.; Zambrano-Rey, G.; Pérez, J. Design of a location and transportation optimization model including quality of service using constrained multinomial logit. Appl. Math. Model. 2021, 89, 428-453. [CrossRef]

34. Aiello, G.; Enea, M.; Muriana, C. Cross-docking transshipment problem approached by non linear programming and simulation analysis. In Proceedings of the 11th International Conference on Modeling and Applied Simulation, MAS 2012, Held at the International Multidisciplinary Modeling and Simulation Multiconference, Wien, Austria, 19-21 September 2012.

35. SteadieSeifi, M.; Dellaert, N.P.; Nuijten, W.; Van Woensel, T.; Raoufi, R. Multimodal freight transportation planning: A literature review. Eur. J. Oper. Res. 2014, 233, 1-15. [CrossRef]

36. Lv, B.; Yang, B.; Zhu, X.; Li, J. Operational optimization of transit consolidation in multimodal transport. Comput. Ind. Eng. 2019, 129, 454-464. [CrossRef] 